\title{
Ritual scalp shaving-a risk factor for community acquired late onset neonatal sepsis
}

\author{
Sen $S,{ }^{1}$ Mondal K B, ${ }^{2}$ Roy A, ${ }^{3}$ Kumar N, ${ }^{4}$ Pant $P,{ }^{5}$ Chatterjee $A^{6}$ \\ ${ }^{1}$ Associate Professor, ${ }^{6}$ Assistant Professor, Calcutta National Medical College, ${ }^{2}$ Associate Professor, \\ ${ }^{3,4} \mathrm{RMO}$ cum Clinical Tutor, ${ }^{5}$ Assistant Professor,North Bengal Medical College,Siliguri.
}

\section{ABSTRACT \\ Background}

Neonatal sepsis is one of the major causes of morbidity and mortality at the community and hospital levels in India. There are several community practices associated with and contributing to Neonatal sepsis, especially late onset variety.

\section{Objective}

To analyze whether scalp shaving is an independent risk factor associated with community acquired late onset neonatal sepsis and the causative organism responsible.

\section{Methods}

This was a prospective, non-interventional, observational study. The study was conducted at two tertiary teaching hospitals in Eastern India from $1^{\text {st }}$ May 2010 to $30^{\text {th }}$ April 2011. A total of 382 babies were diagnosed as Late Onset Neonatal Sepsis and 410 , age and sex matched controls were taken from the Well Baby and Immunization clinics. The patients were clinically screened for sepsis and "septic screen" and blood, urine and CSF cultures sent, as needed.

\section{Results}

History of scalp shaving was present in $46(12.04 \%)$ out of 382 cases of Late Onset Neonatal Sepsis as compared to $20(4.87 \%)$ of 410 matched community controls, the difference was statistically significant $(p<0.005)$.

Positive blood cultures were obtained in 20(43.48\%) out of 46 scalp shaven babies as compared to $118(35.11 \%)$ out of 336 non scalp shaven babies. The commonest organism in babies with scalp shaving was found to be methicillin resistant Staphylococcus aureus(MRSA), whereas the most common organism in non scalp shaven babies was Klebsiella pnuemoniae .

\section{Conclusion}

Scalp shaving appears to be an independent variable associated with community acquired Late Onset Neonatal Sepsis.

\section{Key Words: Scalp shaving, risk factor, neonatal sepsis}


Journal of College of Medical Sciences-Nepal, 2013, Vol-9, No-3,

\section{INTRODUCTION}

Neonatal Sepsis (NNS) remains as one of the most common cause of neonatal mortality and morbidity at the community and hospital based levels in India. Sepsis/meningitis (NNS) (18.6\%) is second to perinatal asphyxia $(28.8 \%)$ as the most common cause of neonatal deaths. ${ }^{1}$

Late Onset Neonatal Sepsis(LONNS) contributes to about $12.2 \%$ of total deaths due to NNS. Apart from the unavoidable causes of LONNS, the avoidable causes include lack of breastfeeding, poor cord care, superficial infections (pyoderma, umbilical sepsis), aspiration of feeds and disruption of skin integrity with needle pricks and use of IV fluids. ${ }^{3}$

Certain local practices are followed in various communities in India and across the world. 4, 5, 6

In West Bengal there is a ritual of scalp shaving especially on the $5^{\text {th }}$ day (age range 4-15 days) in certain minority and tribal communities. No one knows the exact reason why the scalp is shaven but perceptions range from it being a ritual to the prevention of lice infestation and even being the treatment of seborrheic dematitis. In North Bengal, the Rajbanshis and Bihari Muslims followed the custom more as compared to Gorkhas, Bengali Muslims and Hindus. In South Bengal the custom was followed by both Muslim communities but less so by Hindus.

This study was conducted to delineate whether ritual scalp shaving is an independent risk factor in the causation of LONNS and the organisms responsible for it.

\section{METHODS}

Appropriate consent from the caregivers and the approval of the respective hospital ethics committees were taken.
The inclusion criteria for our study was

1. Birth weight $>2.5 \mathrm{~kg}$.

2. Gestational age $(\mathrm{GA})>35$ weeks.

3. Exclusively breastfed.

4. Uneventful intrapartum, peripartum and postpartum period apart from physiological jaundice.

The exclusion criteria were

1. Low birth weight $<2.5 \mathrm{~kg}$.

2. Prematurity GA<35 weeks.

3. Prelacteal usage or artificially fed.

4. Prior or current hospital/nursery/NICU admission for Early Onset Neonatal Sepsis(EONNS), perinatal asphyxia, pathological jaundice, meconium aspiration etc.

There were a total of 382 cases of LONNS included in the study in the two teaching Hospitals (198 cases in North Bengal Medical College \& Hospital-NBMCH and 184 in Calcutta National Medical College \& Hospital-CNMCH) satisfying our inclusion criteria. Altogether 410 randomly selected age, sex and community matched controls were taken from the Well Baby and Immunization clinics (210 cases in NBMCH and 200 cases in $\mathrm{CNMCH}$ ).

All the selected neonates were categorized into two groups-neonates with or without scalp shaving. Each group was assessed clinically and cases clinically suggestive of sepsis underwent

a) Sepsis screening including Total Leukocyte count (TLC), Absolute neutrophil count (ANC), Immature: Total neutrophil ratio, micro ESR, CRP and Chest xray. 
Sen S et al. ritual scalp shaving- a risk factor.
b) Blood culture using BACTEC 9050 instrument (Becton Dickinson, USA).
c) Urine culture and sensitivity.
d) CSF examination for cells using modified Neubaer chamber, Gram stain, proteins, glucose with simultaneous blood glucose using a commercial Glucometer and subsequently confirmed by lab glucose.

Only in $145(37.96 \%)$ cases CSF examination was done when the following parameters were satisfied

i) Infants with positive blood culture

ii) Symptomatic infants with negative blood culture who are empirically treated for the clinical diagnosis of LONNS.

Cases of meningitis was identified by the following criteria $^{7}$
a) positive CSF culture
b) organisms on Gram stain
c) CSF leucocytes $>32$ cells $/ \mathrm{ml}$
d) CSF:blood glucose ratio $<0.8$.

e) CSF Protein $>170 \mathrm{mg} / \mathrm{dL}$

f) The two groups were compared for clinically suspected features, sepsis screen positivity, blood, urine and CSF culture positivity. Culture positive cases were again compared in the respect of organisms isolated.

\section{RESULTS}

The most common instrument used was a khur (a sharpened iron razor) (82.5\%) but disposable razors and blades are being increasingly used (11\%). None of the respondents claimed to see an old blade being reused but khurs are reused and even used on adults. We observed that in LONNS group, the median age of scalp shaving was the $5^{\text {th }}$ day (range 4-20 days) with the median age of onset of infection was on $8^{\text {th }}$ day whereas the median age of onset of infection in non scalp shaved babies was $6^{\text {th }}$ day(range $4-28$ days) . The community barber was the most likely person to shave the scalp. Antiseptics ranging from Dettol, Savlon and alum (Fitkiri) were applied and tap water was used at times. None of the caregivers perceived any harm in the procedure and $77 \%$ felt it to be useful as it was rooted in the tradition of their forefathers. 
TABLE 1.

\begin{tabular}{|c|c|c|c|c|}
\hline \multicolumn{3}{|c|}{ LATE ONSET NNS (n=382) } & \multicolumn{2}{|c|}{ CONTROLS $(n=410)$} \\
\hline & SCALP & NONSCALP & CALP & NONSCALP \\
\hline & SHAVEN & SHAVEN & SHAVEN & SHAVEN \\
\hline No. of neonates* & 46 & 336 & 20 & 390 \\
\hline \multicolumn{5}{|l|}{ Median age of scalp } \\
\hline shaving in days & 5 & NA & 7 & NA \\
\hline Median age of presentation as LONNS & 8 & 6 & NA & NA \\
\hline $\operatorname{Sex}(M: F)$ & $1.12: 1$ & 1.02:1 & $1.15: 1$ & $1.03: 1$ \\
\hline Mean Birth weight (gms) & 2759 & 2818 & 2805 & 2837 \\
\hline \multicolumn{5}{|l|}{ Mean Gestational age (GA) } \\
\hline at birth (in weeks) & 37.2 & 37.5 & 37.3 & 37.9 \\
\hline Mode of delivery-\% of normal deliveries & 82.2 & 75.9 & 80.7 & 75.3 \\
\hline Place of delivery- $\%$ of home deliveries & 60.9 & 55.5 & 58.5 & 53.2 \\
\hline
\end{tabular}

*Statistically significant: $\mathrm{p}<0.005$

Both late onset sepsis and controls including scalp shaven and non scalp shaven were matched with regards to age, sex, birth weight, gestational age at birth, mode and place of delivery. 
TABLE 2.

\begin{tabular}{|c|c|c|c|}
\hline \multirow[b]{3}{*}{ SYMPTOMATOLOGY } & \multicolumn{2}{|c|}{ LATE ONSET NNS $(\mathrm{n}=382)$} & \multirow{3}{*}{ P value } \\
\hline & SCALP & NON SCALP & \\
\hline & SHAVEN $(n=46)$ & SHAVEN $(n=336)$ & \\
\hline 1.Refusal of feeds/feeding difficulty & $25(54.4 \%)$ & $180(53.6 \%)$ & 0.920 \\
\hline 2. Breathing difficulty/grunting & $18(39.1 \%)$ & $141(42.0 \%)$ & 0.714 \\
\hline 3. Fast breathing $(\mathrm{RR}>60 \mathrm{bpm})$ & $22(47.8 \%)$ & $155(46.1 \%)$ & 0.828 \\
\hline 4. Cyanosis & $8(17.4 \%)$ & $38(11.3 \%)$ & 0.235 \\
\hline 5.Abnormal behaviour & $37(80.4 \%)$ & $283(84.2 \%)$ & 0.513 \\
\hline 6. Staring spells/convulsions/shrill cry & $11(23.9 \%)$ & $108(32.1 \%)$ & 0.258 \\
\hline 7. Hypothermia & $9(19.6 \%)$ & $77(22.9 \%)$ & 0.609 \\
\hline 8. Fever/temp. $>38$ degC $^{7}$ & $35(76.1 \%)$ & $275(81.8 \%)$ & 0.349 \\
\hline 9. Jaundice & $7(15.2 \%)$ & $35(10.4 \%)$ & 0.329 \\
\hline 10.Asymptomatic & $6(13.0 \%)$ & $55(16.4 \%)$ & 0.564 \\
\hline 11. Others & $12(26.1 \%)$ & $110(32.7 \%)$ & 0.364 \\
\hline
\end{tabular}

Abnormal behavior and fever is the commonest presentation in both groups, while refusal of feeds and fast breathing also were noted in more than half the babies in both the groups . 
TABLE 3.

\section{LATE ONSET NNS $(\mathrm{n}=382)$}

\section{No. of \\ neonates}

\section{INVESTIGATIONS}

Septic screen Positive

1.Mean Total leukocyte count (TLC)

per $\mathrm{ml}$

2. Mean Absolute neutrophil count

(ANC) per ml

3. Mean I:T ratio

4. Mean CRP in $\mathrm{mg} / \mathrm{dL}$

5. Mean micro ESR ( $\mathrm{mm}$ in $1^{\text {st }}$ hour)

\section{Cases of meningitis}

6. Mean CSF Cells per $\mathrm{mm}^{3}$

7. Mean CSF Glucose in mg/dL

8. Mean CSF Proteins in $\mathrm{mg} / \mathrm{dL}$

$36(9.4 \%)$
$361(94.5 \%)$

SCALP

NON SCALP

SHAVEN $(n=46) \quad$ SHAVEN $(n=336)$

5883

6005

1392

1495

0.22

0.17

8.95

8.99

15

18

$3(6.1 \%)$

$33(9.7 \%)$

86

95

40

45

170

192

The above Table shows Septic screen to be positive in over $90 \%$ cases in both groups. The percentage of cases diagnosed as meningitis using the previous case definition was $9.4 \%$ of all cases of LONNS with the difference between the two groups not being statistically significant. 


\section{TABLE 4}

\begin{tabular}{|c|c|c|c|c|c|c|c|}
\hline \multirow[t]{2}{*}{ Organisms } & \multicolumn{2}{|c|}{$\begin{array}{l}\text { Culture positive cases } \\
\text { among scalp shaved }\end{array}$} & \multicolumn{4}{|c|}{$\begin{array}{l}\text { Culture positive cases among } \\
\text { non scalp shaved }\end{array}$} & \multirow[t]{2}{*}{ Pvalue } \\
\hline & Blood & Urine & CSF & Blood & Urine & CSF & \\
\hline \multicolumn{8}{|l|}{ Methicillin resistant } \\
\hline Staph aureus (MRSA) & $10(21.7 \%)$ & 0 & 0 & $26(7.7 \%)$ & 0 & 0 & $0.004 *$ \\
\hline \multicolumn{8}{|l|}{ Methicillin sensitive Staph } \\
\hline aureus (MSSA) & 1 & 0 & 0 & 3 & 0 & 0 & 0.478 \\
\hline Coagulase negative Staph(CONS) & 2 & 0 & 0 & 12 & 0 & 0 & 0.896 \\
\hline Candida Sp. & 2 & 0 & 0 & 11 & 0 & 0 & 0.803 \\
\hline Acinetobacter & 0 & 0 & 0 & 5 & 0 & 0 & 0.377 \\
\hline Klebsiella Pnuemoniae & $4(8.7 \%)$ & 0 & 0 & $42(12.5 \%)$ & 5 & 0 & 0.183 \\
\hline EColi & 1 & 2 & 0 & 23 & 3 & 0 & 0.626 \\
\hline Proteus sp. & 0 & 0 & 0 & 1 & 1 & 0 & 0.580 \\
\hline \multicolumn{8}{|l|}{ Non lactose fermenting Gram } \\
\hline Negative bacilli(NLFGNB) & 2 & 0 & 0 & 9 & 0 & 0 & 0.609 \\
\hline Psuedomonas aeruginosa & 0 & 1 & 0 & 0 & 0 & 0 & $0.010^{*}$ \\
\hline Others & 0 & 0 & 0 & 1 & 0 & 0 & 0.697 \\
\hline Total & $\begin{array}{c}22 \\
(47.8 \%)\end{array}$ & $\begin{array}{c}1 \\
(2.2 \%)\end{array}$ & 0 & $\begin{array}{c}143 \\
(42.6 \%)\end{array}$ & $\begin{array}{c}9 \\
(2.6 \%)\end{array}$ & 0 & \\
\hline
\end{tabular}

*Statistical significance: $\mathrm{p}<0.05$

MRSA was the commonest and statistically significant(P value 0.004$)$ organism implicated in scalp shaven neonates $(21.7 \%)$ whereas gram negative bacilli especially Klebsiella sp. (12.5\%) was the most common organism in non scalp shaven neonates though it was not statistically significant. 
Journal of College of Medical Sciences-Nepal, 2013, Vol-9, No-3,

\section{DISCUSSION}

Scalp shaving is an ancient custom prevalent among certain communities in Eastern India. No study has yet been done to detect whether scalp shaving is an independent risk factor for LONNS and the causative organisms responsible for it.

The age at presentation of LONNS in our study was day 8 in scalp shaved group and day 6 in no scalp shaved group, which was different from Weber et al ${ }^{12}\left(10^{\text {th }}\right.$ day),and mean weight(2818 gms) was less than Weber et $\mathrm{al}^{12}(3121 \mathrm{gms})$ but reflecting our natonal average of 2800 gms. $^{8}$ There was no significant difference between the scalp and non scalp shaven groups as regards to their age of presentation, sex, birth weight, GA at birth, mode and place of delivery.

When we compared LONNS among scalp shaved and non scalp shaved babies it was found that ritual scalp shaving was an independent and statistically significant risk factor in the causation of LONNS.

Abnormal behavior and fever/temp $>38 \mathrm{deg} \mathrm{C}$ was the most common modes of presentation while refusal of feeds and fast breathing (RR > $60 \mathrm{bpm}$ ) were found in more than half the cases.

Septic screen was Positive in over $90 \%$ in both groups and the incidence of meningitis was comparable in both groups (6.1\% vs 9.7\%).Other studies based in Western countries suggest a lower incidence of meningitis $(134 \text { cases of } 9000 \text { infants }=1.5 \%)^{15}$ but reliable data are lacking from developing countries. Significantly in 45/134 cases blood cultures were negative ${ }^{15}$ but in our study we did not encounter this problem, maybe due to the florid nature of our presentation.
MRSA (21.7\%) was the commonest and statistically significant organism encountered in scalp shaven neonates while Klebsiella pnuemoniae $(12.5 \%)$ was the pathogen commonly isolated in non scalp shaven babies. The second most common pathogen seen was Klebsiella pnuemoniae( $8.7 \%$ ) in scalp shaven neonates and MRSA $(7.7 \%)$ in non scalp shaven neonates. Data on community acquired LONNS were rare and only 3 studies were found. The Kenyan study shows a predominance of E. coli and Group B streptococcus(GBS)while the WHO Young Infant Study Group ,a multi centre trial shows Streptococcus pnuemoniae, Staph aureus, E coli and Salmonella predominating. ${ }^{16,17}$ The Bangladesh study findings were similar to ours showing Staph. aureus as the most common pathogen in community acquired neonatal bacteremia but not necessarily sepsis. ${ }^{18}$ Our study did not show GBS reflecting its paucity in Indian data as well as S.pnuemoniae and Salmonella. Interestingly Candida sp., Acinetobacter and NLFGNB were found. The lone case of Psuedomonas came from a urine culture. In conclusion, Gram positive bacteria such as MRSA and CONS tended to be seen in scalp shaven neonates probably reflecting their dermal origin, while Gram negative bacteria such as Klebsiella, E coli and NLFGNB were seen in non-scalp shaven neonates ,though no statistically significant deference was found between the two groups.

\section{CONCLUSION}

In our study based in North and South Bengal we have seen ritual scalp shaving to be associated with an increased risk of community acquired LONNS. MRSA was found to be statistically significant organism causing LONNS among scalp shaved babies. The authors strongly recommend the abandonment of this 
harmful practice and ask for greater social and political advocacy for the same purpose.

\section{REFERENCES}

1. http://www.iapindia.org/about-and-faq (accessed on 04.07.2011)

2. Kliegman RM, Behrman RE, Jenson HB, Stanton BF. Nelson Textbook of Pediatrics, $18^{\text {th }}$ Ed. Philadelphia: Saunders(Elsevier), 2007 Vol 1: 795

3. Ghai OP, Paul VK, Bagga A. Essential Paediatrics, $7^{\text {th }}$ Ed. Delhi: CBS Publishers, 2009 : 136

4. Kavas DJ, Mullany LC, Katz J, et al Home Care Practices for Newborns in Rural Southern Nepal during the First 2 weeks of Life. J Trop Pediatr 2011 Jun 24 (Epub ahead of print)

5. Kishore MS, Kumar P, Aggarwal AK. Breastfeeding knowledge and practices amongst mothers in a rural population of North India: a community-based study.

J Trop Pediatr 2009 Jun;55(3):183-8. Epub 2008 Dec 12.

6. Sinhababu A, Mukhopadhyay DK, Panja TK et al Infant- and young child-feeding practices in Bankura district, West Bengal, India.J Health Popul Nutr. 2010 Jun;28(3):294-9.

7. Cloherty JP,Eichenwald,Stark AR. Manual of Neonatal Care, $6^{\text {th }}$ Ed. Philadelphia: Lippincott,Williams and Wilkins, 2008. Pg. 652
8. ht tp://w w w. nf h sindia.org/ nutrition_report_for_website_18sep09.pdf (accessed on 04.07.2011.

9. Bang A.T., Bang R.A., Reddy M.H.,et al. Simple clinical criteria to identify sepsis or pneumonia in neonates in the community needing treatment or referral. Pediatr. Infect. Dis. J. 2005;24:335-341.

10. Gupta R., Sachdev H.P., Shah D. Evaluation of the WHO/UNICEF algorithm for integrated management of childhood illness between the ages of one week to two months. Indian Pediatr. 2000;37:383-390.

11. Duke T., Oa O., Mokela D., Oswyn G., et al The management of sick young infants at primary health centres in a rural developing country. Arch. Dis. Child. 2005;90:200-205.

12. Weber M.W., Carlin J.B., Gatchalian S., et al. Predictors of neonatal sepsis in developing countries. Pediatr. Infect. Dis. J. 2003;22:711716.

13. English M., Ngama M., Mwalekwa L., et al. Signs of illness in Kenyan infants aged less than 60 days. Bull. World Health Organ. 2004;82:323-329.

14. Newton O, English M. Young infant sepsis: aetiology, antibiotic susceptibility and clinical signs. Trans $R$ Soc Trop Med Hyg 2007:October : 101(10-4): 959-966.

15. Cloherty JP, Eichenwald, Stark AR. Manual of Neonatal Care, $6^{\text {th }}$ Ed. Philadelphia: Lippincott, Williams and Wilkins, 2008.pg 291 
Journal of College of Medical Sciences-Nepal, 2013, Vol-9, No-3,

16. Berkley J.A., Maitland K., Mwangi I., et al. Use of clinical syndromes to target antibiotic prescribing in seriously ill children in malaria endemic area: observational study. Br. Med. J. 2005;330:995.

17. WHO Young Infants Study Group Bacterial etiology of serious infections in young infants in developing countries: results of a multicenter study. Pediatr. Infect. Dis. J. 1999;18:S17S22.

18. Darmstadt GL, Saha SK, Choi Y et al Population based incidence and Etiology of Community-Acquired Neonatal Bacteremia in Mirzapur, Bangladesh: An Observational Study J Infect Dis 2009 September 15; 200(6): 906915 